\title{
Associations between microvascular function and short-term exposure to traffic-related air pollution and particulate matter oxidative potential
}

Xian Zhang ${ }^{1}$, Norbert Staimer ${ }^{1}$, Tomas Tjoa', Daniel L. Gillen², James J. Schauer ${ }^{3}$, Martin M. Shafer ${ }^{3}$, Sina Hasheminassab ${ }^{4}$, Payam Pakbin ${ }^{4}$, John Longhurst ${ }^{5}$, Constantinos Sioutas ${ }^{4}$ and Ralph J. Delfino ${ }^{1 *}$

\begin{abstract}
Background: Short-term exposure to ambient air pollution has been associated with acute increases in cardiovascular hospitalization and mortality. However, causative chemical components and underlying pathophysiological mechanisms remain to be clarified. We hypothesized that endothelial dysfunction would be associated with mobile-source (traffic) air pollution and that pollutant components with higher oxidative potential to generate reactive oxygen species (ROS) would have stronger associations.

Methods: We carried out a cohort panel study in 93 elderly non-smoking adults living in the Los Angeles metropolitan area, during July 2012-February 2014. Microvascular function, represented by reactive hyperemia index (RHI), was measured weekly for up to 12 weeks $(N=845)$. Air pollutant data included daily data from regional air-monitoring stations, five-day average PM chemical components and oxidative potential in three PM size-fractions, and weekly personal nitrogen oxides $\left(\mathrm{NO}_{\mathrm{x}}\right)$. Linear mixed-effect models estimated adjusted changes in microvascular function with exposure.

Results: $\mathrm{RHI}$ was inversely associated with traffic-related pollutants such as ambient $\mathrm{PM}_{2.5}$ black carbon (BC), $\mathrm{NO}_{x}$, and carbon monoxide (CO). An interquartile range change increase $\left(1.06 \mu \mathrm{g} / \mathrm{m}^{3}\right)$ in 5 -day average $\mathrm{BC}$ was associated with decreased $\mathrm{RHI},-0.093(95 \% \mathrm{Cl}:-0.151,-0.035)$. RHI was inversely associated with other mobile-source components/tracers (polycyclic aromatic hydrocarbons, elemental carbon, and hopanes), and PM oxidative potential as quantified in two independent assays (dithiothreitol and in vitro macrophage ROS) in accumulation and ultrafine PM, and transition metals.
\end{abstract}

Conclusions: Our findings suggest that short-term exposures to traffic-related air pollutants with high oxidative potential are major components contributing to microvascular dysfunction.

Keywords: Microvascular function, Air pollution, Oxidative potential, Particulate matter components

\footnotetext{
* Correspondence: rdelfino@uci.edu

'Department of Epidemiology, School of Medicine, University of California,

Irvine, Irvine 224 Irvine Hall, Irvine, CA 92617-7555, USA

Full list of author information is available at the end of the article
} 


\section{Background}

Previous studies have reported positive associations of cardiovascular morbidity and mortality with short-term exposure to air pollutions [1-3]. While precise pathways underlying these associations have yet to be clarified, it has been hypothesized that the short-term cardiovascular effect of air pollution exposure may be mediated by induction of abnormal vascular responses characterized by reduced endothelium-mediated vasodilation and vessel constriction [2, 4]. Most previous studies have focused on macrovasculature endothelial function assessed using flow-mediated dilatation (FMD) of the brachial artery. However, emerging research shows that dysfunction in the microvascular circulation may be an important dimension of many cardiovascular conditions $[5,6]$. A recent cross-sectional study investigated microvascular function using peripheral arterial tonometry and reported associations between baseline pulse amplitude and short-term exposure to ambient air pollutants, including particulate matter with aerodynamic diameter < $2.5 \mu \mathrm{m}\left(\mathrm{PM}_{2.5}\right)$, black carbon (BC), and particle number concentrations, but not with vasodilator response [7]. A cohort panel study examined microvascular function in the retinal blood vessels and suggested that short-term exposure to higher levels of particulate matter with aerodynamic diameter $<10 \mu \mathrm{m}\left(\mathrm{PM}_{10}\right)$ and $\mathrm{BC}$ may be associated with damage to the retinal microvasculature [8]. In a cross-over study among 53 healthy non-smoking women, UFP exposure was associated with a decrease in microvascular function that was measured by peripheral artery tonometry during physical activity [9]. To our knowledge, no cohort panel studies have evaluated relationships between peripheral microvascular function and air pollution, and there are no data on the importance of particle oxidative potential or specific particle components on microvascular function.

It is important to note in this regard that ambient air particles are a complex mixture of numerous components originating from different sources [1], each with complex particle size distributions. This may result in different adverse health effects. An increasing toxicology literature suggests that ultrafine particles (aerodynamic diameter smaller than approximately $0.1-0.2 \mu \mathrm{m}$ ) as compared with larger particles, which can dominate $\mathrm{PM}_{2.5}$ mass, may have greater adverse cardiovascular effects because of higher deposition efficiency and larger surface area [10], as well as higher redox activity [11]. In the present paper, we used repeated measurements to evaluate associations between microvascular function and size-fractionated PM (including their chemical composition and oxidative potential), in an elderly cohort living in the Los Angeles metropolitan area. Many previous epidemiological studies (especially time series of morbidity and mortality outcomes) have relied on uncharacterized $\mathrm{PM}_{2.5}$ and $\mathrm{PM}_{10}$ mass data, often from local regulatory agencies. In order to thoroughly characterize the exposure, our present study measured chemical composition in coarse $\left(\mathrm{PM}_{2.5-10}\right)$, accumulation $\left(\mathrm{PM}_{0.18-2.5}\right)$, and ultrafine $\left(\mathrm{PM}_{0.18}\right)$ size fractions of PM $[12,13]$.

\section{Methods \\ Study design}

This study was a cohort panel design consisting of repeated measures of outcomes and exposures for 93 elderly non-smoking adults (age $\geq 65$ years) living in the Los Angeles metropolitan area. Each subject effectively serves as his/her own control in this design. The elderly population is particularly susceptible to the adverse cardiovascular effects of air pollution exposure [1]. We followed subjects for up to 12 weeks, 6 weeks each during the warm season (July-October) and cool season (November-February) to incorporate seasonal differences in air pollution levels [14]. Exclusion criteria included: 1) employment outside of the monitored community (18 km radius); 2) smoking within the last 12 months; 3) exposure to environmental tobacco smoke at home or on a regular basis at other locations; 4) psychiatric disorder, dementia, alcohol or drug abuse; 5) dialysis treatment or renal failure; 6) daily oral corticosteroids; 7) active cancer; and 8) medical conditions that prevent the subject from giving blood or from performing the plethysmography procedure for measuring microvascular function. Observations following the previous 7 days when subjects reported any acute infection $(8.16 \%)$ were excluded a priori given their known major impacts on systemic inflammation.

\section{Outcome measurement}

We collected background questionnaires at the beginning of the study that included medical history, socioeconomic status, medications, history of active smoking, and environmental exposure profile. Concurrently, a fasting blood sample was taken to obtain plasma lipid profiles and glucose levels.

At each follow-up visit, microvascular function (specifically arteriolar) was measured by forearm blood flow dilatation response to brachial artery occlusion using a noninvasive plethysmograph (EndoPAT 2000, Itamar Medical, Israel), yielding the reactive hyperemia index (RHI) score. A low RHI score indicates impaired endothelial function. The measurement protocol has been described previously [15]. Briefly, finger plethysmography was recorded on both arms in supine position in a quiet private room. Each measurement consists of a 5-min baseline measurement, a 5-min occlusion of the brachial artery (at least $60 \mathrm{mmHg}$ above the systolic blood pressure) and a 5-min post-occlusion measurement (reactive- 
hyperemia response). Occlusion was performed on the non-dominant upper arm (test arm) and no occlusion was given on the dominant arm (control arm). RHI was the outcome variable, which was calculated as the increase in peripheral arterial tone signal amplitude (post-occlusion to pre-occlusion ratio). Systolic and diastolic blood pressures were measured before the EndoPAT using the Omron 7015IT (Omron Health Care, Kyoto, Japan) with direct computer linkage [16]. Due to space limitations in our clinics, our blood pressure measurements were taken under the non-standard conditions, namely insufficient time for subjects to rest ( $<5 \mathrm{~min}$ ), as well as noisy and potentially stressful level of social activity in the common areas. Thesefore, blood pressure measurements were only used to assist in setting the cuff inflation pressure for the EndoPAT. Daily medication use and acute infectious disease status were ascertained by a patient self-report diary, filled out daily and collected at each weekly visit.

\section{Exposure measurements}

Ambient air pollutants included hourly concentrations of U.S. Environmental Protection Agency criteria air pollutants, including $\mathrm{PM}_{2.5}$, carbon monoxide $(\mathrm{CO})$, nitrogen oxides $\left(\mathrm{NO}_{\mathrm{x}}, \mathrm{NO}+\mathrm{NO}_{2}\right)$ and ozone $\left(\mathrm{O}_{3}\right)$, and meteorological data including temperature and relative humidity. These data were obtained from the South Coast Air Quality Management District (SCAQMD) monitoring stations in the targeted study areas that included an approximate $18 \mathrm{~km}$ radius around the central air monitoring stations. Daily exposure data were calculated from the hourly data, when $\geq 75 \%$ of daily data were available. Missing rates for daily $\mathrm{PM}_{2.5}, \mathrm{CO}, \mathrm{NO}_{\mathrm{x}}$, and $\mathrm{O}_{3}$ were $7.38 \%, 6.83 \%, 25.96 \%$ and $9.02 \%$, respectively. Daily missing data for ambient air pollutants were imputed using regression modeling, predicted by the exposure data from the stations with non-missing data in the study area. A description of missing imputation methods is provided in Additional file 1: online supplement 1 and Table S1. Ambient air pollutant concentrations for 1-day, 3-day, 5-day and 7-day averages preceding clinic follow-ups were calculated from the daily data. This span of averaging times was representative of regression effect estimates for all averaging times across the previous week.

Our study team collected hourly $\mathrm{PM}_{2.5}$ BC (Aethalometer model AE22, Magee Scientific, Berkeley, CA) and 5-day integrated concentrations of $\mathrm{PM}_{0.18}$ (ultrafine mode), $\mathrm{PM}_{0.18-2.5}$ (accumulation mode) and $\mathrm{PM}_{2.5-10}$ (coarse mode) (MOUDI, model 100-1, MSP, Inc., Minneapolis, MN) at the University of Southern California (USC) monitoring sites. Five days of continuous particle collection before each clinic visit was necessary to obtain a sufficient amount of sample for the chemical and oxidative potential assays described below. The USC monitoring site for the first year of study was approximately $3 \mathrm{~km}$ southwest of the SCAQMD central air monitoring station where criteria air pollutants were measured in downtown Los Angeles (see Additional file 1: Figure S1). Our USC site for the second year of study was at the same location as the SCAQMD station in Anaheim. Following gravimetric measurements using a highly precise $( \pm 0.001 \mathrm{mg})$ microbalance (Mettler Toledo Inc., Columbus, OH, USA), filters were sectioned and disturbed for PM chemical characterization. To quantify the elemental and organic carbon (EC and $\mathrm{OC}$, respectively) content of the samples, a $1.5 \mathrm{~cm}^{2}$ punch of the quartz/aluminum filters was analyzed by National Institute for Occupational Safety and Health Thermal Optical Transmission method [17]. Speciated organics, including total polycyclic hydrocarbons (PAHs), hopanes, and organic acid (see Additional file 1: Table S2) were measured using gas chromatography mass spectrometry [18]. Total elemental composition of the samples was measured by digestion of a section of the Teflon filter-collected PM using a microwave added, sealed bomb, mixed acid digestion. Digests were subsequently analyzed by high-resolution inductively coupled plasma sector field mass spectrometry (SF-ICPMS). The present study focuses on the measured transition metals ( $\mathrm{V}, \mathrm{Cr}, \mathrm{Mn}, \mathrm{Ni}, \mathrm{Cu}$, and $\mathrm{Fe}$ ) because of their potential to induce oxidative stress through Fenton reactions.

In vitro redox activity of PM was measured by two different methods: alveolar macrophage reactive oxygen species (ROS) assay [19], representing the biotic oxidative potential of particle mixtures, and dithiothreitol (DTT) activity [20], representing capacity to generate abiotic chemically-produced ROS. Biotic ROS production was quantified by extracting the filter with $1.00 \mathrm{ml}$ of Milli-Q water. We then exposed rat alveolar macrophage cells (NR8383, American Type Culture Collection) and the fluorescent probe DCFH-DA in 96-well plates to both unfiltered (total ROS) and filtered (watersoluble ROS) (0.22 $\mu \mathrm{m}$ polypropylene syringe filter) PM extracts. Fluorescence intensity then was measured using a plate reader and represents the cell-based oxidative generating capacity of PM. A model of microbial particles, un-opsonized Zymosan (a $\beta$-1,3-polysachharide of D-glucose) served as a positive ROS control as it binds to Toll-like receptor- 2 on macrophage cells and then activates a strong respiratory burst and ROS production. ROS results are reported in $\mu \mathrm{g}$ Zymosan equivalent units per $\mathrm{m}^{3}$ air based the product of $\mu \mathrm{g}$ Zymosan equivalents/ $\mu$ g sample times the $\mu \mathrm{g}$ PM per $\mathrm{m}^{3}$ air. Details of the macrophage ROS method are described in detail elsewhere [19]. DTT activity was quantified using a wellestablished method [21] on extracts of 5-day composites of the three different size-fractionated PM from quartz 
filters. DTT activity represents the ability of the PM extract to catalyze electron transfer from DTT to oxygen, thereby generating superoxide radicals.

Seven-day average personal exposures to $\mathrm{NO}_{\mathrm{x}}$ were collected using the Ogawa passive badge sampler (Ogawa \& Co. USA, Inc. Pompano Beach, FL). Subjects were instructed to wear the sampler clipped outside of clothing and placed near the bedside. Personal $\mathrm{NO}_{\mathrm{x}}$ was collected on cellulose fiber filters and concentrations were determined by a spectrophotometer at a wavelength of $545 \mathrm{~nm}$ in our laboratory following manufacturer's specification [22]. To capture the combined health-related effects of temperature and relative humidity, we calculated hourly heat index using methods developed in a previous study [23].

\section{Statistical analysis}

To account for the clustering of longitudinal repeated measurements taken on each subject, we performed repeated measurement analysis to investigate the association between RHI and air pollutants using a linear mixed effects model that included a random subject intercept to account for the correlation of repeated measures. The general form of this model is given by:

$$
Y_{i, j}=a_{i,}+\alpha Z_{i,}+\beta X_{i, j}+\gamma W_{i, j}+\varepsilon_{i, j}
$$

Here, $i$ indexes subject $(\mathrm{i}=1, \ldots, 93), j$ indexes outcome measurement on each subject $(j=1, \ldots, 12) . Y_{i, j}$, is the outcome measurement, $a_{i}$ is the random subject intercept, $Z_{i}$ is a vector of time-independent subject characteristics (e.g. sex or medical conditions), $X_{i, j}$ is a vector of timedependent air pollutant exposure levels (of primary interest), $W_{i, j}$ is a vector of time-dependent covariates (time trend, medications, and weather), and $\varepsilon_{i, j}$ denotes random within-person error in the outcome measurement. The best covariance structure of $\varepsilon{ }_{i, j}$ was selected using Akaike's information criterion (AIC) and was the autoregressive moving average (ARMA) $(1,1)$ covariance structure. To compare associations across different pollutants, the magnitude of effect was expressed relative to an interquartile range (25th to 75 th percentile) difference in each pollutant concentrations. All statistical analyses were performed using $\mathrm{R}$ version 3.0.3 ( $\mathrm{R}$ Foundation for Statistical Computing, Vienna, Austria) or SAS 9.3 software (SAS, Cary, NC).

Time invariant subject characteristics were controlled by study design and the specified repeated measures model, and hence were not included as adjustment covariates. Heat index was inversely associated with RHI, albeit nonsignificant. An a priori covariate was heat index with the same lag as the pollutant to adjust for the effects of weather. Other time-dependent potential confounders were tested in the models. Exercise [24] and/or food intake [25] can change peripheral blood flow and potentially affect microvascular function. In the model, we adjusted exercise and/or food intake within an hour before subjects came to the clinic as a potential confounding factor for microvascular function. Days of gas stove use per week were significantly associated with increased personal $\mathrm{NO}_{\mathrm{x}}$ and were adjusted in the models of personal $\mathrm{NO}_{\mathrm{x}}$ because the exposure of interest was outdoor fossil fuel sources of $\mathrm{NO}_{\mathrm{x}}$. Long-term temporal trend was tested by including cubic splines using different knots for day of study. However, it did not significantly change the estimation or improve model fit. As a result, adjustment for temporal trend was not included in our final model.

The impact of influential observations was assessed using the Cook's D statistic and standardized residual diagnostics, at both the individual observations level and clustered subjects level [26]. No evidence to suggest a departure from normality was observed and no significant influential observations were detected.

Risk factors for cardiovascular disease may be potential effect modifiers of the association between microvascular function and air pollution. Accordingly we tested them by incorporating multiplicative interactions with air pollutants in exploratory analyses. These risk factors included age ( $>75$ years old), sex, obesity (body mass index: $\mathrm{BMI} \geq 30 \mathrm{~kg}$ weight $/ \mathrm{m}^{2}$ height), measured hypertension (systolic blood pressure $>140$ or diastolic blood pressure $>90$ ), diabetes mellitus, hypercholesterolemia by history, high cholesterol (total cholesterol $>200 \mathrm{mg}$ / $\mathrm{dL}$ ), high low-density lipoprotein (LDL) concentration $(\geq 140 \mathrm{mg} / \mathrm{dL}$ ), total cholesterol/high-density lipoprotein $(\mathrm{HDL})>3.5$, history of cardiovascular disease, and former smokers. We also tested differences in association between the cohort in Los Angeles and the cohort in Anaheim. Evidence of significant interaction was considered at a nominal product term $p$-value $<0.1$ to avoid increased type II errors in these hypothesis-generating analyses.

Several sensitivity analyses were conducted. First, to investigate potential exposure error, we restricted the analysis to the subjects who lived within the $90^{\text {th }}$ percentile of subjects' residential distance to the stations $(11.3 \mathrm{~km}$ for the SCAQMD monitoring stations and $13.1 \mathrm{~km}$ for the USC monitoring sites). Second, we limited the analysis to measured ambient exposure, rather than exposure including imputed data from the next nearest station. Third, we excluded days with extreme heat index $\left(<52.5\right.$ and $>75.04,10^{\text {th }}$ percentile and $90^{\text {th }}$ percentile of the heat index during the study period, respectively) because the decreased ventilation at subjects' residential buildings during those days may lead to an increased exposure error. Finally, we tested for the independent effects of photochemically-related and primary air pollutants by using two-pollutant models with $\mathrm{O}_{3}$ and another primary pollutant. 


\section{Results}

Detailed information on the characteristics of study subjects are listed in Table 1. The subjects were 65 to 96 years old, and two-thirds of the subjects were female. All were currently non-smokers, though approximately $40 \%$ were former smokers. Among the 93 subjects, there are 59 non-Hispanic Whites, 9 Hispanics, 11 African Americans, 9 Asians and 5 other race/ethnicities. Approximately one-third of subjects were obese (BMI $\geq$ $\left.30 \mathrm{~kg} / \mathrm{m}^{2}\right)$ and one-third were overweight $\left(25 \mathrm{~kg} / \mathrm{m}^{2} \leq\right.$ $\mathrm{BMI}<30 \mathrm{~kg} / \mathrm{m}^{2}$ ). More than $60 \%$ of subjects had history of a hypertension, and over half had a history of dyslipidemia. Sixteen percent had diabetes. The mean RHI score was 1.94, which was in the normal endothelial function range $(>1.67)$ according to the EndoPAT manufacturer's manual [27].

Table 2 provides metrics for the $24 \mathrm{~h}$-average concentrations of ambient air pollutants, 7-day average personal $\mathrm{NO}_{x}$, and 5-day average size-fractionated PM air pollutants. Data for specific transition metals is presented in the Additional file 1: Table S3. For 24h ambient pollutants at the central sites, $\mathrm{NO}_{\mathrm{x}}$ had the highest missing rates (29.95\%), and all other pollutants had less than $10 \%$ of missing data. Personal $\mathrm{NO}_{\mathrm{x}}$ had $15.91 \%$ missing data due to measurement errors where $\mathrm{NO}_{\mathrm{x}}$ concentration was less than $\mathrm{NO}_{2}$, subject noncompliance, or incorrect sampling

Table 1 Characteristics of subjects $(N=93)$

\begin{tabular}{|c|c|}
\hline Characteristic & Mean $\pm \mathrm{SD}$ or $\mathrm{N}(\%)$ \\
\hline Age (years) $\pm S D$ & $74.9 \pm 7.6$ \\
\hline Body mass index $\left(\mathrm{kg} / \mathrm{m}^{2}\right) \pm \mathrm{SD}$ & $27.8 \pm 5.5$ \\
\hline Overweight (25-29.9) & 35 (37.6) \\
\hline Obesity $(\geq 30)$ & $28(30.1)$ \\
\hline Male & $25(26.9)$ \\
\hline Former smoker & $39(41.9)$ \\
\hline Reactive hyperemia index (RHI) score & $1.95(0.4)$ \\
\hline \multicolumn{2}{|l|}{ Cardiovascular history } \\
\hline Coronary artery disease & $16(17.2)$ \\
\hline Congestive heart failure & $8(8.6)$ \\
\hline Stroke & $9(9.7)$ \\
\hline Hypertension & $62(66.7)$ \\
\hline Hypercholesterolemia (by history) & $50(53.8)$ \\
\hline \multicolumn{2}{|l|}{ Lipid Profile } \\
\hline Total cholesterol > $200 \mathrm{mg} / \mathrm{dL}$ & $37(39.8)$ \\
\hline $\mathrm{LDL}-\mathrm{C}>130 \mathrm{mg} / \mathrm{dL}$ & $29(31.2)$ \\
\hline $\mathrm{HDL}-\mathrm{C}<50 \mathrm{mg} / \mathrm{dL}$ for women; $<40$ mg/dL for men & $25(26.9)$ \\
\hline Adult-onset diabetes mellitus & $21(22.6)$ \\
\hline \multicolumn{2}{|l|}{ Medications: } \\
\hline Anti-hypertensive medications & $62(66.7)$ \\
\hline HMG-CoA reductase inhibitors (statins) & $45(45.2)$ \\
\hline
\end{tabular}

times. For size-fractionated PM components, up to 4 of the planned 48 weeks were missing due to equipment failure or power outages at the Anaheim site. Ninety-seven percent of the study period had average $24 \mathrm{~h} \mathrm{PM}_{2.5}$ below the National Air Quality Standard recommended upper limit of $35 \mu \mathrm{g} / \mathrm{m}^{3}$. Total PAHs and hopanes were higher in $\mathrm{PM}_{0.18-2.5}$ than in $\mathrm{PM}_{0.18}$. Both DTT and ROS were highest in $\mathrm{PM}_{0.18-2.5}$, and were higher in $\mathrm{PM}_{2.5-10}$ than in $\mathrm{PM}_{0.18}$. For most transition metals (V, Cr, Mn, $\mathrm{Cu}$ and $\mathrm{Fe}$ ), the highest mass concentrations were observed in $\mathrm{PM}_{2.5-10}$ (Additional file 1: Table S3).

As expected, concentrations of traffic-related air pollutants ( $\mathrm{BC}, \mathrm{NO}_{\mathrm{x}}, \mathrm{CO}, \mathrm{EC}, \mathrm{PAHs}$, and hopanes) were higher in the more densely urban Los Angeles region than in the more suburban Anaheim (Additional file 1: Table S4). The correlation between 5-day averages of $\mathrm{PM}_{2.5} \mathrm{BC}$ and $\mathrm{EC}$ were much lower in Los Angeles $(R=0.54)$ than in Anaheim $(R=0.93)$. This is likely because the sampling sites were different in Los Angeles but were the same in Anaheim (Additional file 1: Figure S1). The correlation between personal $\mathrm{NO}_{\mathrm{x}}$ and ambient $\mathrm{NO}_{\mathrm{x}}, \mathrm{BC}$ and $\mathrm{CO}$ was much stronger in Anaheim than in Los Angeles (Additional file 1: Table S5). This could be because of a greater influence of micro-environmental exposures, including local traffic, in Los Angeles than in Anaheim. Given these regional differences, we present correlations for combined regions in Tables 3 and 4 after mean-centering exposures by region. Spearman correlations of ambient air pollutants showed strong positive correlations among the trafficrelated air pollutants $\left(\mathrm{BC}, \mathrm{NO}_{\mathrm{x}}, \mathrm{CO}, \mathrm{R}>0.87\right.$ ) (Table 3$)$. These pollutants correlated weakly to $\mathrm{PM}_{2.5}$, especially in Los Angeles (Additional file 1: Table S5). Moderate to strong inverse correlations were observed for trafficrelated air pollutants and $\mathrm{O}_{3}$, with stronger correlations in Anaheim than Los Angeles. For 5-day sizefractionated PM, total mass in $\mathrm{PM}_{0.18}$ was not correlated with total mass in $\mathrm{PM}_{0.18-2.5}$ and inversely correlated with total mass in $\mathrm{PM}_{2.5-10}$ (Table 4). Total PAHs and hopanes were strongly correlated $(R=0.89$ 0.91), suggesting that the primary source of PAHs was traffic since hopanes are unique tracers of vehicular emissions in the Los Angeles basin and found in the lubricant oils of diesel and gasoline vehicles [28]. Correlations between total PAHs and $\mathrm{OC}$ were strong in both $\mathrm{PM}_{0.18}$ and $\mathrm{PM}_{0.18-2.5}$ while the correlations between total PAHs and EC were stronger in $\mathrm{PM}_{0.18}$ than in $\mathrm{PM}_{0.18-2.5}$. Correlation between DTT and OC/EC was strong in $\mathrm{PM}_{0.18}$, and weak in $\mathrm{PM}_{0.18-2.5}$ and $\mathrm{PM}_{2.5-10}$, suggesting that oxidative potential may have different chemical determinants in these size fractions. Transition metals (except for V) were strongly correlated with OC/EC, total ROS and DTT in $\mathrm{PM}_{2.5-10}(\mathrm{R}=0.59$ 0.72) (Additional file 1: Table S6). 
Table 2 Descriptive statistics of air pollutant measurements

\begin{tabular}{|c|c|c|c|c|c|}
\hline & N (Missing) & Mean (SD) & IQR & Min & Max \\
\hline \multicolumn{6}{|c|}{ Personal Exposures (7-day average) } \\
\hline $\mathrm{NO}_{x}(\mathrm{ppb})$ & $729(116)$ & $28.07(19.66)$ & 20.87 & 2.21 & 160.13 \\
\hline \multicolumn{6}{|c|}{ Ambient Exposures (24h Averages) } \\
\hline Black Carbon $\left(\mu \mathrm{g} / \mathrm{m}^{3}\right)$ & $320(16)$ & $1.28(0.85)$ & 1.06 & 0.21 & 5.21 \\
\hline $\mathrm{PM}_{2.5}\left(\mu \mathrm{g} / \mathrm{m}^{3}\right)$ & $309(27)$ & $17.56(7.70)$ & 9.62 & 3.83 & 49.23 \\
\hline $\mathrm{CO}(\mathrm{ppm})$ & $311(25)$ & $0.54(0.24)$ & 0.32 & 0.11 & 1.59 \\
\hline Ozone (ppb) & $303(33)$ & $23.16(9.25)$ & 12.66 & 1.33 & 48.51 \\
\hline $\mathrm{NO}_{x}(\mathrm{ppb})$ & $241(95)$ & $35.42(27.69)$ & 31.02 & 3.6 & 175.63 \\
\hline Heat Index $\left(F^{\circ}\right)$ & $366(0)$ & $66.09(8.39)$ & 12.56 & 42.57 & 84.33 \\
\hline \multicolumn{6}{|c|}{ Size-fractionated PM (5-day average) } \\
\hline \multicolumn{6}{|l|}{ Mass $\left(\mu \mathrm{g} / \mathrm{m}^{3}\right)$} \\
\hline $\mathrm{PM}_{0.18}$ & $45(3)$ & $2.41(0.86)$ & 1.13 & 1.17 & 4.81 \\
\hline $\mathrm{PM}_{0.18}-\mathrm{PM}_{2.5}$ & $45(3)$ & $8.64(3.21)$ & 4.01 & 4.40 & 19.43 \\
\hline $\mathrm{PM}_{2.5}-\mathrm{PM}_{10}$ & $44(4)$ & $14.91(6.78)$ & 7.80 & 4.45 & 35.36 \\
\hline \multicolumn{6}{|l|}{ Total PAH (ng/m³) } \\
\hline $\mathrm{PM}_{0.18}$ & $45(3)$ & $0.32(0.22)$ & 0.30 & 0.03 & 0.77 \\
\hline $\mathrm{PM}_{0.18}-\mathrm{PM}_{2.5}$ & $45(3)$ & $0.46(0.45)$ & 0.46 & 0.21 & 1.98 \\
\hline \multicolumn{6}{|l|}{ Hopanes $\left(\mathrm{ng} / \mathrm{m}^{3}\right)$} \\
\hline $\mathrm{PM}_{0.18}$ & $45(3)$ & $0.17(0.12)$ & 0.19 & 0.01 & 0.44 \\
\hline $\mathrm{PM}_{0.18}-\mathrm{PM}_{2.5}$ & $45(3)$ & $0.21(0.20)$ & 0.21 & 0.00 & 0.82 \\
\hline \multicolumn{6}{|l|}{$\mathrm{OA}\left(\mu \mathrm{g} / \mathrm{m}^{3}\right)$} \\
\hline $\mathrm{PM}_{0.18}$ & $45(3)$ & $26.21(10.84)$ & 14.45 & 9.64 & 57.98 \\
\hline $\mathrm{PM}_{0.18}-\mathrm{PM}_{2.5}$ & $45(3)$ & $18.12(13.99)$ & 16.76 & 0.56 & 61.43 \\
\hline \multicolumn{6}{|l|}{$O C\left(\mu \mathrm{g} / \mathrm{m}^{3}\right)$} \\
\hline $\mathrm{PM}_{0.18}$ & $45(3)$ & $1.18(0.39)$ & 0.42 & 0.47 & 2.35 \\
\hline $\mathrm{PM}_{0.18}-\mathrm{PM}_{2.5}$ & $45(3)$ & $1.54(0.78)$ & 1.11 & 0.53 & 3.48 \\
\hline $\mathrm{PM}_{2.5}-\mathrm{PM}_{10}$ & $45(3)$ & $0.67(0.22)$ & 0.30 & 0.28 & 1.12 \\
\hline \multicolumn{6}{|l|}{$\mathrm{EC}\left(\mu \mathrm{g} / \mathrm{m}^{3}\right)$} \\
\hline $\mathrm{PM}_{0.18}$ & $45(3)$ & $0.26(0.13)$ & 0.16 & 0.09 & 0.60 \\
\hline $\mathrm{PM}_{0.18}-\mathrm{PM}_{2.5}$ & $45(3)$ & $0.15(0.12)$ & 0.18 & 0.01 & 0.45 \\
\hline $\mathrm{PM}_{2.5}-\mathrm{PM}_{10}$ & $45(3)$ & $0.04(0.03)$ & 0.05 & 0.00 & 0.09 \\
\hline \multicolumn{6}{|l|}{ Total ROS $\left(\mu \mathrm{g} Z \mathrm{ym} / \mathrm{m}^{3}\right)^{a}$} \\
\hline $\mathrm{PM}_{0.18}$ & $45(3)$ & $19.8(12.21)$ & 16.60 & 2.10 & 53.20 \\
\hline$P M_{0.18}-P M_{2.5}$ & $45(3)$ & $136.69(94.62)$ & 125.90 & 26.20 & 394.00 \\
\hline $\mathrm{PM}_{2.5}-\mathrm{PM}_{10}$ & $44(4)$ & $60.19(49.73)$ & 76.45 & 8.70 & 181.00 \\
\hline \multicolumn{6}{|c|}{ Water-soluble ROS ( $\mu \mathrm{g} Z \mathrm{ym} / \mathrm{m}^{3}$ ) } \\
\hline $\mathrm{PM}_{0.18}$ & $45(3)$ & $16.74(11.49)$ & 13.60 & 1.50 & 50.60 \\
\hline $\mathrm{PM}_{0.18}-\mathrm{PM}_{2.5}$ & $45(3)$ & 117.05 (87.66) & 95.60 & 18.60 & 421.90 \\
\hline $\mathrm{PM}_{2.5}-\mathrm{PM}_{10}$ & $44(4)$ & $25.04(22.63)$ & 34.05 & 2.40 & 84.20 \\
\hline \multicolumn{6}{|c|}{ Dithiothreitol $\left(\mathrm{nmol} / \mathrm{min} / \mathrm{m}^{3}\right)$} \\
\hline $\mathrm{PM}_{0.18}$ & $45(3)$ & $0.10(0.05)$ & 0.06 & 0.02 & 0.24 \\
\hline $\mathrm{PM}_{0.18}-\mathrm{PM}_{2.5}$ & $45(3)$ & $0.26(0.08)$ & 0.08 & 0.12 & 0.48 \\
\hline $\mathrm{PM}_{2.5}-\mathrm{PM}_{10}$ & $44(4)$ & $0.24(0.11)$ & 0.14 & 0.10 & 0.53 \\
\hline
\end{tabular}


Table 2 Descriptive statistics of air pollutant measurements (Continued)

\begin{tabular}{|c|c|c|c|c|c|}
\hline \multicolumn{6}{|c|}{ Transition metals ${ }^{\mathrm{b}}\left(\mathrm{ng} / \mathrm{m}^{3}\right)$} \\
\hline $\mathrm{PM}_{0.18}$ & $45(3)$ & $49.20(40.43)$ & 56.2438 & 7.22 & 153.39 \\
\hline $\mathrm{PM}_{0.18}-\mathrm{PM}_{2.5}$ & $45(3)$ & $72.02(52.86)$ & 46.0233 & 12.89 & 237.11 \\
\hline $\mathrm{PM}_{2.5}-\mathrm{PM}_{10}$ & $44(4)$ & 396.57 (171.18) & 219.9526 & 111.97 & 914.57 \\
\hline
\end{tabular}

Abbreviations: IQR interquartile range, $C O$ carbon monoxide, $P M$ particulate matter, $P A H s$ polycyclic aromatic hydrocarbons, $O C$ organic carbon, $E C$ elemental carbon, ROS Reactive oxygen species

aym: $\mu \mathrm{g}$ Zymosan equivalent units

${ }^{\mathrm{b}}$ Total sum of transition metals include $\mathrm{V}, \mathrm{Cr}, \mathrm{Mn}, \mathrm{Ni}, \mathrm{Cu}$ and $\mathrm{Fe}$

Figure 1 presents the relationships between RHI, as a measure of microvascular function, and interquartile range increases in ambient air pollutants measured daily and 5-day size-fractionated PM components. RHI was inversely associated with ambient $\mathrm{BC}$ and $\mathrm{NO}_{\mathrm{x}}$ for 1through 7-day averaging times, and with $\mathrm{CO}$ for 3- and 5-day averages, indicating impaired endothelial function with exposure to these pollutants. RHI was not significantly associated with ambient $\mathrm{PM}_{2.5}$ or $\mathrm{O}_{3}$ at any averaging time, or with 7-day average personal $\mathrm{NO}_{\mathrm{x}}$ (Fig. 1a). The strongest associations with ambient daily exposures were observed for 5-day averages. For example, an interquartile range increase in 5-day average $\mathrm{BC}$ $\left(1.06 \mu \mathrm{g} / \mathrm{m}^{3}\right)$ was associated with an RHI decrease of -0.093 (95\% confidence intervals, CI: $-0.151,-0.035$ ). We observed no significant regional differences of the association between RHI and ambient exposures, except for $\mathrm{PM}_{2.5}$ at 7 -day average (product term $p=0.08$ ), with a positive association in Los Angeles and a negative association in Anaheim ( $95 \% \mathrm{CI}$; for both regional associations were wide and contained 0.00) (Additional file 1: Figure S2).

RHI was not significantly associated with 5-day total mass of $\mathrm{PM}_{0.18}$ or $\mathrm{PM}_{0.18-2.5}$, but was marginally associated with total mass in $\mathrm{PM}_{2.5-10}(-0.046,95 \% \mathrm{CI}:-0.095$, 0.004; Fig. 1b). We did observe that RHI was inversely associated with total PAHs, hopanes and DTT in $\mathrm{PM}_{0.18}$, marginally inversely associated with $\mathrm{PM}_{0.18} \mathrm{EC}$, total and

Table 3 Spearman correlation matrix of ambient, personal air pollutants and heat index ${ }^{a}$

\begin{tabular}{|c|c|c|c|c|c|c|}
\hline & $\mathrm{BC}$ & $\mathrm{CO}$ & $\mathrm{NO}_{x}$ & $\mathrm{PM}_{2.5}$ & $\mathrm{O}_{3}$ & Heat Index $\left(F^{\circ}\right)$ \\
\hline \multicolumn{7}{|c|}{$24 \mathrm{~h}$ averages of ambient exposures } \\
\hline $\mathrm{BC}\left(\mu \mathrm{g} / \mathrm{m}^{3}\right)$ & & 0.87 & 0.90 & 0.33 & -0.69 & -0.27 \\
\hline CO (ppm) & & & 0.90 & 0.27 & -0.73 & -0.32 \\
\hline $\mathrm{NO}_{x}(\mathrm{ppb})$ & & & & 0.20 & -0.77 & -0.32 \\
\hline $\mathrm{PM}_{2.5}\left(\mu \mathrm{g} / \mathrm{m}^{3}\right)$ & & & & & -0.06 & 0.09 \\
\hline $\mathrm{O}_{3}(\mathrm{ppb})$ & & & & & & 0.54 \\
\hline \multicolumn{7}{|c|}{ 7-day averages of personal exposure ${ }^{b}$} \\
\hline Personal $\mathrm{NO}_{x}(\mathrm{ppb})$ & 0.47 & 0.45 & 0.47 & 0.16 & -0.43 & -0.25 \\
\hline
\end{tabular}

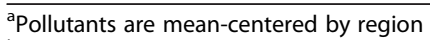

${ }^{b}$ Correlations for personal $\mathrm{NO}_{\mathrm{x}}$ were calculated with 7-day average of ambient pollutants and heat index water-soluble ROS, but not $\mathrm{PM}_{0.18}$ organic acids (OA) or $\mathrm{OC}$ (representing a mixture of primary and secondary organic aerosols). RHI was associated more strongly (inversely) with EC, total and water-soluble ROS in $\mathrm{PM}_{0.18-2.5}$ than in the other particle sizes. RHI also was inversely associated with $\mathrm{OC}$ in $\mathrm{PM}_{2.5-10}$ (a minor fraction of that particle size), but not in the other particle sizes, suggesting that the fraction of primary and secondary OC may be different in $\mathrm{PM}_{2.5-10}$ or that $\mathrm{OC}$ is correlated with other components (e.g. metals) associated with RHI (Additional file1: Table S6). We found that RHI was inversely associated with all transition metals in $\mathrm{PM}_{2.5-10}$, with the transition metals $\mathrm{Cr}, \mathrm{Mn}, \mathrm{Ni}, \mathrm{Cu}$ and $\mathrm{Fe}$ but not $\mathrm{Ni}$ or $\mathrm{V}$ in $\mathrm{PM}_{0.18-2.5}$ and with the transition metals $\mathrm{Cr}, \mathrm{Mn}, \mathrm{Ni}$, $\mathrm{Cu}$, and $\mathrm{Ni}$ but not $\mathrm{V}$ in $\mathrm{PM}_{0.18}$. (Fig. 2).

For two-pollutant models, the magnitude of the nonsignificant associations for $\mathrm{PM}_{2.5}$ and personal $\mathrm{NO}_{\mathrm{x}}$ were largely unchanged with $\mathrm{O}_{3}$ in the model (Fig. 3a). Estimations of association for ambient BC, $\mathrm{CO}, \mathrm{NO}_{\mathrm{x}}$ showed even greater decreases in microvascular function by $45-113 \%$ in RHI after adjusting for $\mathrm{O}_{3}$ than in single-pollutant models (Fig. 1a), although the confidence intervals were wider. We also noted that adjusting for $\mathrm{BC}$ in the model with $\mathrm{O}_{3}$, the estimations of association for $\mathrm{O}_{3}$ changed from positive in single-pollutant models (Fig. 1a) to negative in two-pollutant models (Fig. 3a), and became significant for 1- and 3-day averages. To address the possibility of an interaction between primary and secondary air pollutants ( $\mathrm{BC}$ and $\mathrm{O}_{3}$, respectively), we further tested a model with the product term of $\mathrm{BC}$ and $\mathrm{O}_{3}$ and found significant positive interactions $(p$ $<0.1$ ) of BC and $\mathrm{O}_{3}$ on RHI at 3-day and 5-day averages, suggesting synergism (Additional file 1: Figure S3). The estimates of association for 5-day size-fractionated $\mathrm{PM}$ and components remained relatively unchanged after adjusting for $\mathrm{O}_{3}$ (Fig. 3b).

Associations also persisted when we restricted the analysis to subjects living within the $90^{\text {th }}$ percentile of all subjects' residential distance to monitoring stations (Additional file 1: Figure S4). When we excluded imputed ambient exposure data, the associations for $\mathrm{PM}_{2.5}, \mathrm{O}_{3}$ and $\mathrm{BC}$ remained similar. Conversely these associations became slightly weaker for $\mathrm{NO}_{\mathrm{x}}$ and $\mathrm{CO}$ 
Table 4 Spearman correlation matrix of 5-day average of components in size-fractionated PM ${ }^{\mathrm{a}}$

\begin{tabular}{|c|c|c|c|c|c|c|c|c|c|c|c|c|c|c|c|c|c|c|c|c|c|c|c|c|c|c|}
\hline \multirow[b]{2}{*}{ Pollutants } & \multicolumn{9}{|l|}{$\mathrm{PM}_{0.18}$} & \multicolumn{10}{|c|}{$\mathrm{PM}_{0.18-2.5}$} & \multicolumn{7}{|c|}{$\mathrm{PM}_{2.5-10}$} \\
\hline & $\begin{array}{l}\text { T } \\
\text { PAHs }\end{array}$ & $\begin{array}{l}\text { Hopa- } \\
\text { nes }\end{array}$ & $\mathrm{OA}$ & OC & $\mathrm{EC}$ & $\begin{array}{l}\text { T } \\
\text { ROS }\end{array}$ & $\begin{array}{l}\text { WS } \\
\text { ROS }\end{array}$ & DTT & $\begin{array}{l} \\
\text { Metals }\end{array}$ & $\begin{array}{l}\mathrm{T} \\
\text { mass }\end{array}$ & $\begin{array}{l}\text { T } \\
\text { PAHS }\end{array}$ & $\begin{array}{l}\text { Hopa- } \\
\text { nes }\end{array}$ & $\mathrm{OA}$ & OC & EC & $\begin{array}{l}\text { ROS } \\
\text { ROS }\end{array}$ & $\begin{array}{l}\text { WS } \\
\text { ROS }\end{array}$ & DTT & $\begin{array}{l}\mathrm{T} \\
\text { Metals }\end{array}$ & $\begin{array}{l} \\
\text { mass }\end{array}$ & OC & $\mathrm{EC}$ & $\begin{array}{l}\text { T } \\
\text { ROS }\end{array}$ & $\begin{array}{l}\text { WS } \\
\text { ROS }\end{array}$ & $\mathrm{DTT}$ & $\begin{array}{l}\text { T } \\
\text { Metals }\end{array}$ \\
\hline \multicolumn{27}{|l|}{$\overline{\mathrm{PM}_{0.18}}$} \\
\hline Mass & 0.58 & 0.63 & 0.29 & 0.74 & 0.62 & 0.47 & 0.45 & 0.72 & 0.70 & 0.00 & 0.50 & 0.44 & 0.24 & 0.52 & 0.24 & 0.18 & 0.14 & 0.38 & 0.57 & -0.32 & 0.26 & 0.11 & -0.40 & -0.36 & 0.34 & 0.23 \\
\hline T PAHS & & 0.89 & 0.51 & 0.80 & 0.75 & 0.10 & 0.11 & 0.76 & 0.81 & 0.13 & 0.94 & 0.86 & 0.71 & 0.87 & 0.37 & 0.18 & 0.21 & 0.52 & 0.68 & -0.60 & 0.55 & 0.51 & -0.30 & -0.42 & 0.57 & 0.61 \\
\hline Hopanes & & & 0.60 & 0.82 & 0.72 & 0.17 & 0.16 & 0.79 & 0.78 & 0.13 & 0.85 & 0.78 & 0.58 & 0.80 & 0.42 & 0.16 & 0.20 & 0.56 & 0.68 & -0.47 & 0.49 & 0.46 & -0.27 & -0.38 & 0.58 & 0.61 \\
\hline OA & & & & 0.52 & 0.27 & 0.09 & 0.11 & 0.42 & 0.30 & 0.21 & 0.54 & 0.65 & 0.55 & 0.54 & 0.25 & 0.08 & 0.23 & 0.45 & 0.37 & -0.33 & 0.32 & 0.40 & -0.10 & -0.15 & 0.66 & 0.35 \\
\hline OC & & & & & 0.83 & 0.45 & 0.44 & 0.86 & 0.80 & 0.08 & 0.73 & 0.72 & 0.43 & 0.76 & 0.46 & 0.26 & 0.28 & 0.61 & 0.70 & -0.36 & 0.53 & 0.36 & -0.25 & -0.29 & 0.49 & 0.57 \\
\hline EC & & & & & & 0.42 & 0.42 & 0.77 & 0.68 & 0.19 & 0.64 & 0.51 & 0.36 & 0.76 & 0.58 & 0.39 & 0.28 & 0.57 & 0.66 & -0.23 & 0.57 & 0.31 & -0.07 & -0.07 & 0.29 & 0.67 \\
\hline T ROS & & & & & & & 0.98 & 0.41 & 0.25 & 0.01 & -0.02 & -0.02 & -0.15 & 0.12 & 0.34 & 0.30 & 0.28 & 0.17 & 0.18 & 0.28 & 0.20 & -0.04 & 0.12 & 0.13 & -0.01 & 0.09 \\
\hline WS ROS & & & & & & & & 0.42 & 0.23 & -0.01 & -0.01 & 0.00 & -0.12 & 0.13 & 0.35 & 0.28 & 0.27 & 0.15 & 0.16 & 0.26 & 0.21 & 0.00 & 0.12 & 0.15 & 0.00 & 0.11 \\
\hline $\mathrm{DTT}$ & & & & & & & & & 0.81 & 0.00 & 0.68 & 0.59 & 0.30 & 0.63 & 0.50 & 0.14 & 0.17 & 0.44 & 0.68 & -0.42 & 0.45 & 0.25 & -0.27 & -0.37 & 0.40 & 0.45 \\
\hline T Metals ${ }^{\mathrm{b}}$ & & & & & & & & & & 0.00 & 0.76 & 0.61 & 0.33 & 0.64 & 0.32 & 0.13 & 0.18 & 0.48 & 0.80 & -0.46 & 0.50 & 0.33 & -0.40 & -0.51 & 0.42 & 0.51 \\
\hline \multicolumn{27}{|l|}{$\mathrm{PM}_{0.18-2.5}$} \\
\hline Mass & & & & & & & & & & & 0.18 & 0.12 & 0.21 & 0.36 & 0.19 & 0.65 & 0.67 & 0.48 & 0.24 & 0.26 & 0.15 & 0.29 & 0.47 & 0.43 & 0.32 & 0.24 \\
\hline T PAHs & & & & & & & & & & & & 0.90 & 0.73 & 0.85 & 0.32 & 0.09 & 0.22 & 0.49 & 0.63 & -0.54 & 0.60 & 0.56 & -0.29 & -0.44 & 0.67 & 0.65 \\
\hline Hopanes & & & & & & & & & & & & & 0.77 & 0.81 & 0.23 & 0.08 & 0.18 & 0.47 & 0.52 & -0.60 & 0.55 & 0.51 & -0.34 & -0.43 & 0.71 & 0.52 \\
\hline OA & & & & & & & & & & & & & & 0.70 & 0.15 & -0.03 & 0.14 & 0.35 & 0.27 & -0.53 & 0.31 & 0.47 & -0.20 & -0.30 & 0.61 & 0.37 \\
\hline OC & & & & & & & & & & & & & & & 0.47 & 0.31 & 0.35 & 0.62 & 0.63 & -0.42 & 0.59 & 0.56 & -0.09 & -0.16 & 0.63 & 0.67 \\
\hline EC & & & & & & & & & & & & & & & & 0.41 & 0.46 & 0.25 & 0.27 & 0.15 & 0.31 & 0.33 & 0.27 & 0.29 & 0.18 & 0.52 \\
\hline T ROS & & & & & & & & & & & & & & & & & 0.84 & 0.37 & 0.30 & 0.27 & 0.11 & 0.14 & 0.33 & 0.47 & 0.11 & 0.14 \\
\hline WS ROS & & & & & & & & & & & & & & & & & & 0.40 & 0.32 & 0.22 & 0.16 & 0.26 & 0.43 & 0.44 & 0.30 & 0.25 \\
\hline DTT & & & & & & & & & & & & & & & & & & & 0.57 & -0.16 & 0.42 & 0.35 & 0.14 & 0.01 & 0.41 & 0.53 \\
\hline T Metals ${ }^{\mathrm{b}}$ & & & & & & & & & & & & & & & & & & & & -0.37 & 0.51 & 0.23 & -0.11 & -0.20 & 0.32 & 0.53 \\
\hline \multicolumn{27}{|l|}{$\mathrm{PM}_{2.5-10}$} \\
\hline Mass & & & & & & & & & & & & & & & & & & & & & -0.04 & -0.01 & 0.60 & 0.67 & -0.31 & -0.06 \\
\hline OC & & & & & & & & & & & & & & & & & & & & & & 0.55 & 0.06 & 0.00 & 0.32 & 0.75 \\
\hline EC & & & & & & & & & & & & & & & & & & & & & & & 0.19 & 0.11 & 0.39 & 0.51 \\
\hline T ROS & & & & & & & & & & & & & & & & & & & & & & & & 0.87 & -0.11 & 0.23 \\
\hline WS ROS & & & & & & & & & & & & & & & & & & & & & & & & & -0.20 & 0.09 \\
\hline DTT & & & & & & & & & & & & & & & & & & & & & & & & & & 0.39 \\
\hline
\end{tabular}

Abbreviations: DTT dithiothreitol, EC elemental carbon, OA Organic acids, OC organic carbon, $P M$ particulate matter, ROS reactive oxygen species, $T$ total, WS water-soluble Bold numbers indicate correlation values $\geq 0.60$ and $P<0.05$

a Pollutants are mean-centered by region

${ }^{\mathrm{b}}$ Total sum of transition metals include $\mathrm{V}, \mathrm{Cr}, \mathrm{Mn}, \mathrm{Ni}, \mathrm{Cu}$ and $\mathrm{Fe}$ 

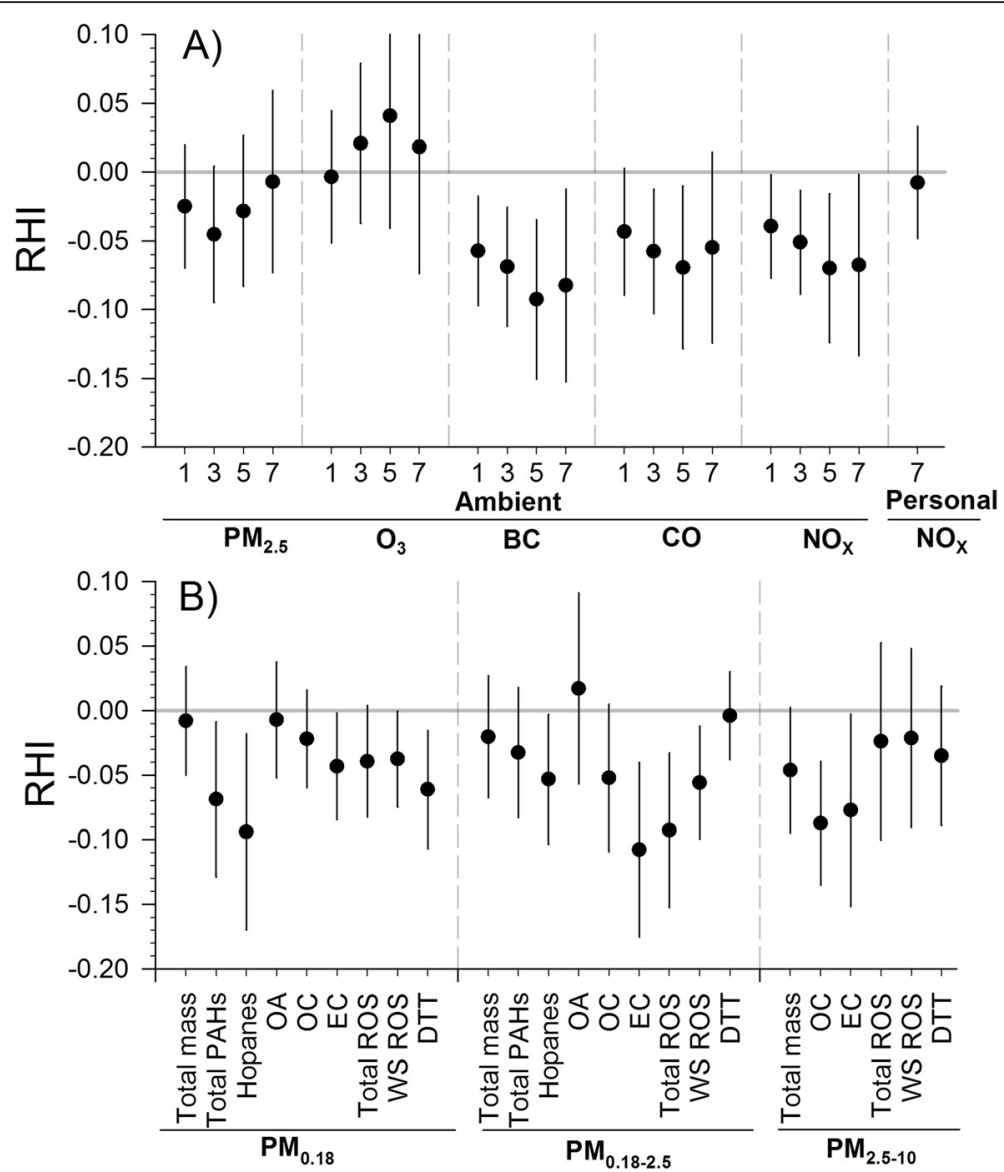

Fig. 1 Association of microvascular function with a one interquartile range increase of ambient and personal pollutants. Exposures were averaged across 1 day, 3 days, 5 days, and 7 days preceding each subject's reactive hyperemia index (RHI) measurement (a) and the PM components in three different sizefractions for exposures averaged across 5 days preceding each subject's RHI measurement (b). BC: black carbon; DTT: dithiothreitol; EC: elemental carbon; OA: Organic acids; OC: organic carbon; PAHs: polycyclic aromatic hydrocarbons; PM particulate matter; ROS: reactive oxygen species; WS: water-soluble

(Additional file 1: Figure S5). We did not observe significant changes when we excluded days with extreme heat index (data not shown).

We evaluated effect modification of associations between RHI and 5-day average air pollutants (except for

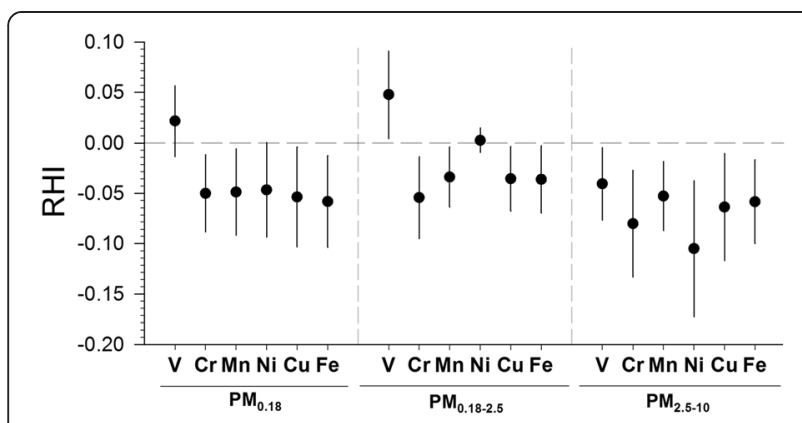

Fig. 2 Association of microvascular function with a one interquartile range increase of selected transition metals. Transition metals were measured in three size-fractions for exposures averages across 5 days preceding each subject's reactive hyperemia index (RHI) measurement personal $\mathrm{NO}_{\mathrm{x}}$ since only 7-day averages were available). Five-day averages were selected because we found that the largest and most consistent associations with RHI were for 5-day averages. Also, this is the averaging time for the PM components. We observed evidence of effect modification by smoking status on the association between RHI and exposures to trafficrelated air pollutants (ambient $\mathrm{BC}, \mathrm{CO}, \mathrm{NO}_{\mathrm{x}}$, personal $\mathrm{NO}_{\mathrm{x}}$, PAHs, hopanes, EC) with stronger inverse associations estimated for former smokers than for individuals who never smoked (Fig. 4). Subjects who were obese generally had stronger inverse associations of RHI with exposure to air pollutants, except for secondary pollutants (Fig. 5). Significant modifying effects $(p<0.1)$ were observed for exposures to ambient $\mathrm{PM}_{2.5} \mathrm{BC}$, and $\mathrm{EC}$ in $\mathrm{PM}_{0.18}$ and $\mathrm{PM}_{0.18-2.5}$. We observed no evidence of statistically significant interaction between exposures and age, sex, diabetes status, lipid factors, hypertension or history of cardiovascular diseases (data not shown). 

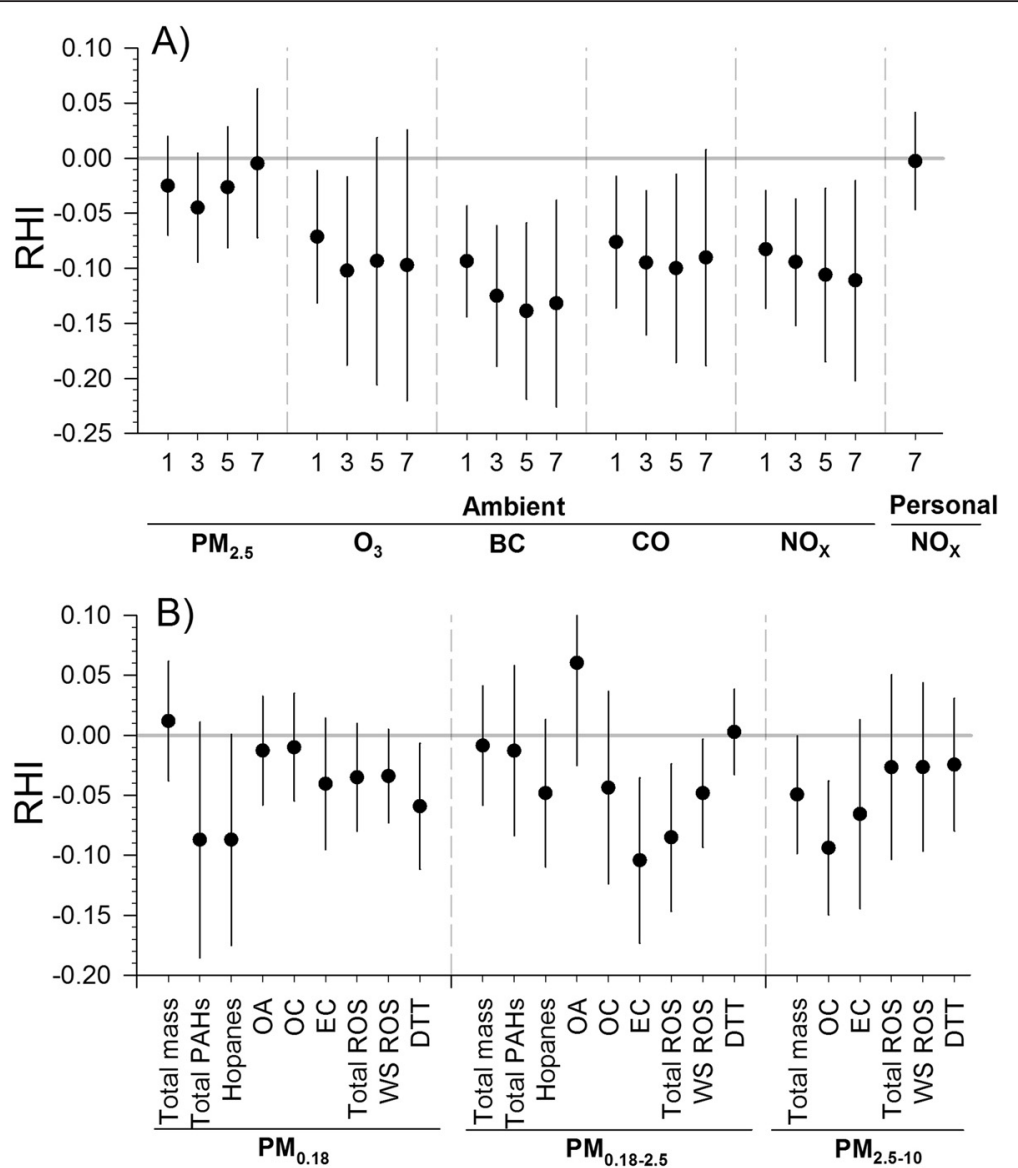

Fig. 3 Sensitivity analysis of relations between microvascular function and air pollution: two-pollutant models. Association of reactive hyperemia index $(\mathrm{RHI})$ with a one interquartile range increase of ambient and personal air pollutants for exposures averaged across 1 day, 3 days, 5 days, and 7 days preceding each subject's measurement (a) and the PM components in three different size-fractions for exposures averaged across 5 days preceding each subject's RHI measurement $(\mathbf{b})$. The sensitivity analysis is adjusting for ozone with the same averaging time, except for the ozone model, which adjusts for black carbon with the same averaging time. BC: black carbon; DTT: dithiothreitol; EC: elemental carbon; OA: Organic acids; OC: organic carbon; PAHs: polycyclic aromatic hydrocarbons; PM particulate matter; ROS: reactive oxygen species; WS: water-soluble

\section{Discussion}

We found decreased microvascular endothelial function in relation to increases in short-term exposure to air pollution. These associations were observed primarily for markers of primary fossil fuel combustion sources (EC, $\mathrm{BC}, \mathrm{CO}, \mathrm{NO}_{\mathrm{x}}, \mathrm{PAHs}$, and hopanes). One of the strongest associations was observed for 5-day average $\mathrm{BC}$ with an interquartile range increase associated with a RHI decrease of -0.093 . There is no standardized guideline for the clinical relevance of changes in RHI. However, previous studies indicate that a low RHI score is independently associated with adverse cardiovascular outcomes. For example, the hazard ratio for cardiovascular events per 1.1 increase of RHI showed a significant decrease in risk 0.761 (CI: 0.691, 0.832) after controlling for other risk factors in a high risk cohort of 528 subjects [6].

We used hourly ambient air monitoring data over the seven days preceding outcome measurements and found that the strongest associations were for 5-day averages.
Several controlled exposure studies have found that diesel exhaust is associated with impaired vascular function from as early as $2 \mathrm{~h}$ after the exposure and up to $24 \mathrm{~h}[29,30]$. Comparisons with the present study are difficult because previous studies used experimental study designs incorporating higher exposure levels (i.e. $300 \mu \mathrm{g} / \mathrm{m}^{3}$ particulate mass concentrations).

We found stronger associations of RHI with PAHs and hopanes in $\mathrm{PM}_{0.18}$ than in the $\mathrm{PM}_{0.18-2.5}$, which includes larger particles. In the Los Angeles metropolitan area, most outdoor PAHs in $\mathrm{PM}_{0.18}$ are expected to be from mobile sources [31]. The strong correlation of PAHs $(R=0.89)$ with hopanes (source markers of vehicular emissions) is consistent with this expectation. PAHs were more strongly correlated with DTT in $\mathrm{PM}_{0.18}$ than in $\mathrm{PM}_{0.18-2.5}$ indicating that PAHs in $\mathrm{PM}_{0.18}$ were more redox active. This is consistent with our findings that even though the concentration of PAHs and hopanes were higher in $\mathrm{PM}_{0.18-2.5}$ than in 


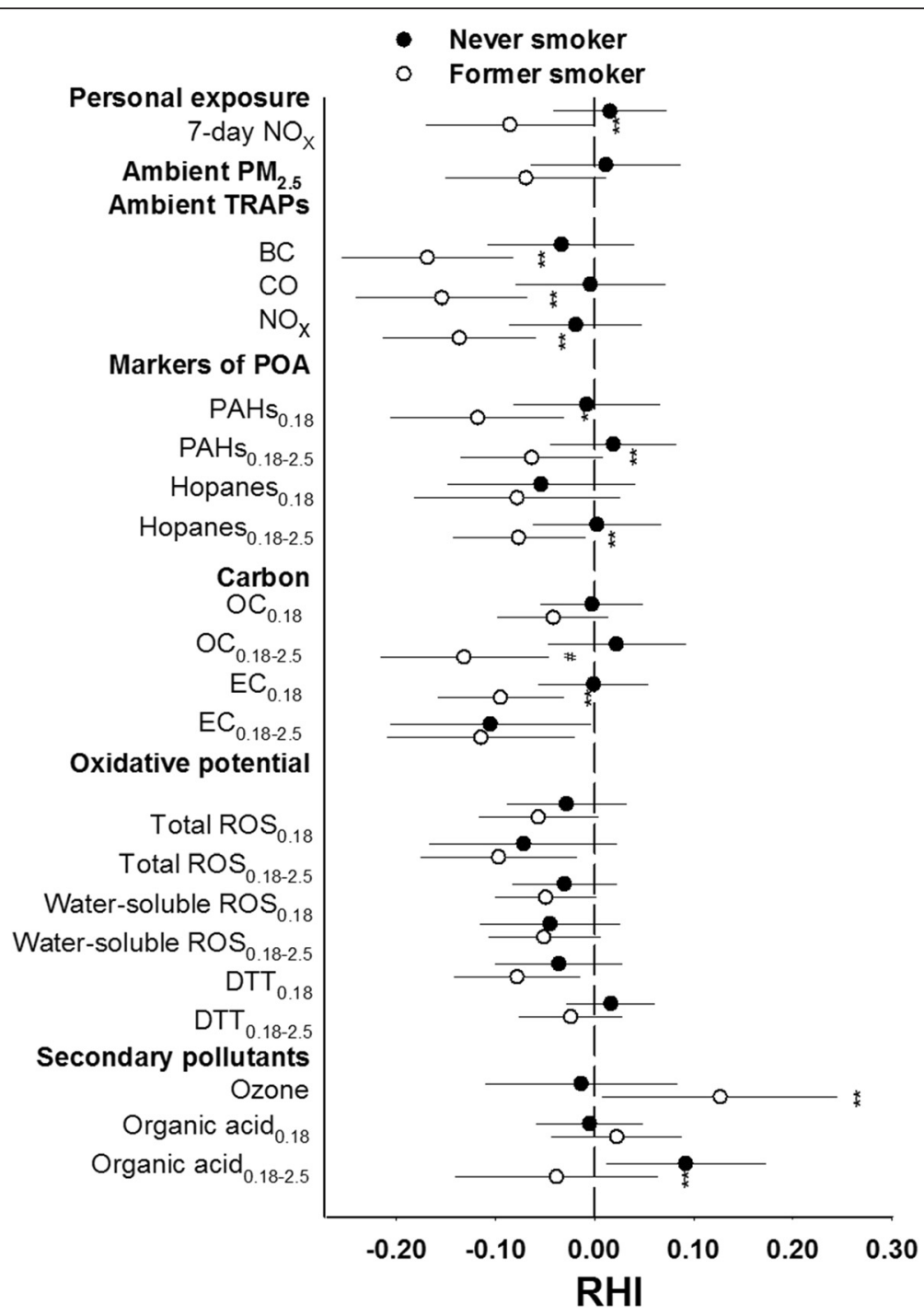

Fig. 4 Effect modification of relations between microvascular function and air pollution by never and former smoker. Association of reactive hyperemia index $(\mathrm{RHI})$ with one interquartile increase of selected air pollutant exposures averaged across 5 days preceding each subject's RHI measurement. ${ }^{*} p<0.1,{ }^{* *} p<0.05,{ }^{*} p<0.01$, compared with no effect modification by smoking status. BC: black carbon; DTT: dithiothreitol; EC: elemental carbon; OC: organic carbon; PAHs: polycyclic aromatic hydrocarbons; PM particulate matter; ROS: reactive oxygen species

$\mathrm{PM}_{0.18}$ (Table 2), we observed stronger associations of RHI with PAHs and hopanes in $\mathrm{PM}_{0.18}$. The spatial variation in UFP is much greater than larger particle size fractions. Therefore, exposure error is expected to be much greater when regional monitoring data are used and this complicates direct comparisons between size fractions [32,33]. Our previous panel study did not have $\mathrm{PM}_{0.18}$ components but did find that circulating biomarkers of inflammation were associated with PAHs and hopanes measured in quasi-ultrafine $\mathrm{PM}_{0.25}$ [34]. The biomarkers were not associated with other organic components or transition metals in the $\mathrm{PM}_{0.25}$. Furthermore, PAHs confounded nominal associations of biomarkers with $\mathrm{PM}_{0.25}$ mass. In a follow-up panel study with organic components also measured in the accumulation mode size fraction $\left(\mathrm{PM}_{0.25-2.5}\right)$, we found that exposure markers of combustion-related air pollutants including $\mathrm{PM}_{0.25-2.5}$ PAHs and/or $\mathrm{PM}_{0.25}$ PAHs were positively associated with expression of genes in inflammatory and oxidative stress pathways, including NFE2L2, Nrf2-mediated genes (HMOX1, NQO1, and SOD2), CYP1B1, IL1B, and SELP [35]. In toxicological studies, it has been demonstrated that ultrafine particles have high levels of organic compounds and metals, and were more capable of generating ROS [36] and pro-inflammatory responses [37].

This is the first epidemiological study reporting a decrease in microvascular function in relation to markers of PM oxidative potential. This is consistent with our previous novel findings for associations with chemical 


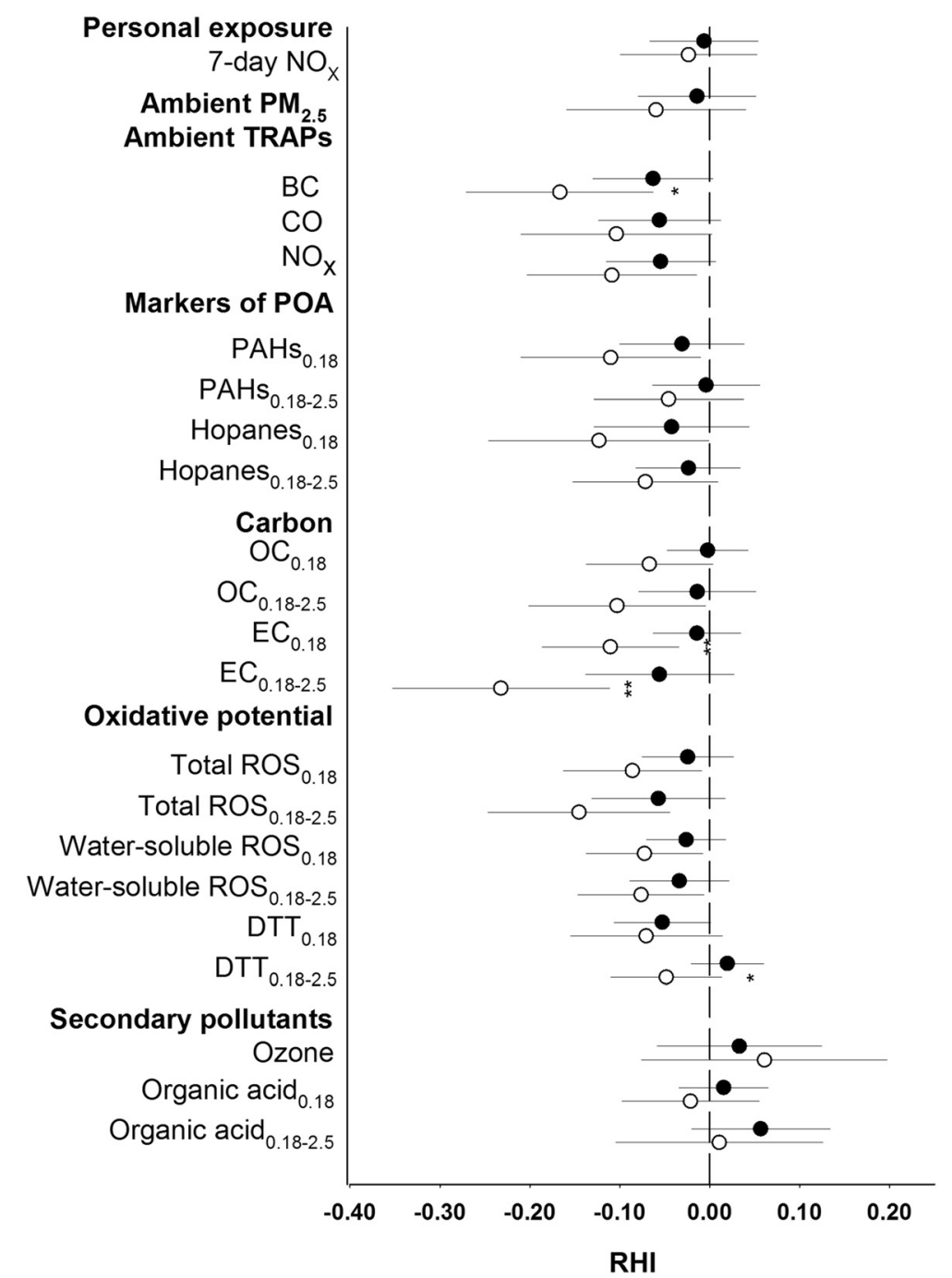

Fig. 5 Effect modification of relations between microvascular function and air pollution by obesity status. Association of RHI score with one interquartile range increase of selected air pollutant exposures averaged across 5 days preceding each subject's reactive hyperemia index (RHI) measurement: ${ }^{*} p<0.1,{ }^{* *} p<0.05$, compared with no effect modification by obesity status. BC: black carbon; BMl: body mass index; DTT: dithiothreitol; EC: elemental carbon; OC: organic carbon; PAHs: polycyclic aromatic hydrocarbons; PM particulate matter; ROS: reactive oxygen species

components such as PAHs with known pro-oxidant effects in cell cultures [38]. As noted by Higashi et al. [39], the underlying mechanisms may be increased production of ROS during oxidative stress that inactivates nitric oxide (NO) production. Decreased NO impairs endothelial function leading to an imbalance in microvascular function.

Specifically, we observed inverse associations of microvascular function with PM oxidative potential both in $\mathrm{PM}_{0.18}$ and $\mathrm{PM}_{0.18-2.5}$ with DTT associations stronger in $\mathrm{PM}_{0.18}$ and macrophage ROS associations stronger in $\mathrm{PM}_{0.18-2.5}$. Estimated associations of microvascular function with total ROS was stronger than with watersoluble ROS in $\mathrm{PM}_{0.18-2.5}$ while no such difference was observed in $\mathrm{PM}_{0.18}$. The DTT assay is a chemical (acellular) assay based on the ability of redox-active compounds to transfer electrons from DTT to oxygen [40] while the ROS assay represents cellular production of ROS measured using rat alveolar macrophage cells exposed to particle extracts [19]. The highest oxidative potential measured by both assays were in $\mathrm{PM}_{0.18-2.5}$. However, the correlations between the two assays in $\mathrm{PM}_{0.18}$ and $\mathrm{PM}_{0.18-2.5}$ were weak $(\mathrm{R}=0.37$ to 0.42$)$, and not correlated in $\mathrm{PM}_{2.5-10}$ ( -0.11 and -0.20 for DTT 
with total ROS and water-soluble ROS, respectively). Together with the observation of different associations for DTT and macrophage ROS across the size-fractions, this finding may indicate that these two assays are sensitive to different components of PM and those components lead to health effects that vary depending on particle size distribution and source. Therefore, these two assays complement each other and are informative of the importance of PM under different exposure conditions. Further studies are needed to better understand the relationships between PM components and the associated DTT and macrophage ROS activities.

Few cohort panel studies of within-subject exposureresponse relations have examined effects on endothelial function by exposure to ambient air pollution [8, 41-43]. Some [41, 43] but not all [42] found that short-term exposure to $\mathrm{PM}_{2.5}$, sulfate, and $\mathrm{BC}$ were associated with FMD of the brachial artery. Most previous studies have investigated the function of forearm conduit arteries. However, the peripheral microvasculature share more similarities in development and anatomy with the microvasculature of the heart than conduit arteries and may be an early cardiovascular risk indicator $[44,45]$.

A few air pollution studies have evaluated microvascular function. For example, one cross-sectional study of the Framingham Heart Study Offspring Cohorts, Ljungman et al. [7], found no consistent associations between the air pollution exposures, including $\mathrm{BC}$, and microvascular response. However, a cross-sectional study design may not efficiently capture acute air pollution effects given the high temporal and spatial variation in ambient air pollution levels and the variation of outcome and confounders between subjects. Louwies et al. [8] is the only previous study conducted to investigate acute within-subject responses of microvascular function. They examined retinal microvasculature using fundus image analysis in a panel of 84 healthy adults, 22-63 years of age. Consistent with our results, they found that impaired microvascular responses were associated with exposure to $\mathrm{BC}$ but with a more acute response (at lag 1 and lag 2 day BC). Many reasons may contribute to the inconsistency among panel studies including: different methods to assess microvascular function, different study population, exposure error, different composition of pollutants, and duration and frequency of exposure assessment. Compared with these above panel studies, our sample size is large, with more repeated measures $(N=845)$, and with more detailed characteristics of the air pollutants.

We found that "protective" effects of $\mathrm{O}_{3}$ were confounded by $\mathrm{BC}$, a marker of primary combustion sources. However, the inverse associations between $\mathrm{BC}$ and microvascular function persisted after adjusting for $\mathrm{O}_{3}$ indicating a robust estimate for $\mathrm{BC}$. This may be attributable partly to meteorological determinants and partly to the observation that high concentrations of a correlated primary pollutant like NO is associated to a reduction of $\mathrm{O}_{3}$ [46], both causing the inverse correlation between primary pollutants and $\mathrm{O}_{3}$. Therefore, the "protective" effect of $\mathrm{O}_{3}$ may be attributed to low levels of primary air pollutants. Another explanation is $\mathrm{O}_{3}$ exposure error, given that indoor $\mathrm{O}_{3}$ is generally much lower than outdoor concentrations, especially when are windows closed and air conditioning is in use [47].

Unexpectedly, our measurement of personal exposures to $\mathrm{NO}_{\mathrm{x}}$ was not associated with microvascular function. One explanation may be subject non-compliance, although we have no direct evidence of this. It is possible that the device was not worn as instructed (exposed to outside air and not held in a pocket or purse), or not worn for the 7-day time period requested. In addition, the device is a passive sampler subject to face velocity effects from variations in airflow. Lastly, even though our personal exposure models adjusted for indoor origin of $\mathrm{NO}_{\mathrm{x}}$, it was possible that this was not fully addressed since the source of adjustment data was from selfadministered daily diaries.

We found that microvascular function was significantly inversely associated with $\mathrm{OC}$ in $\mathrm{PM}_{2.5-10}$, but not in $\mathrm{PM}_{1.8}$ or $\mathrm{PM}_{1.8-2.5}$. This may because of the strong correlation between $\mathrm{OC}$ and inorganic species such as total $\mathrm{Cr}, \mathrm{Mn}, \mathrm{Ni}, \mathrm{Cu}$ and $\mathrm{Fe}(\mathrm{R}=0.74-0.82)$ in $\mathrm{PM}_{2.5-10}$ (Additional file 1: Table S6). These metals had the highest concentrations in $\mathrm{PM}_{2.5-10}$ (Additional file 1: Table S3) and they can generate reactive oxygen species by Fenton-type reactions, resulting in adverse health effects [48]. Indeed we found that decreased RHI was significantly associated with $\mathrm{Cr}, \mathrm{Mn}, \mathrm{Ni}, \mathrm{Cu}$ and $\mathrm{Fe}$ in $\mathrm{PM}_{2.5-10}$ with the strongest association observed with $\mathrm{Ni}(-0.156$, 95 \% CI:-238, -0.074, Fig. 2). However, co-regression of $\mathrm{PM}_{2.5-10}$ OC with $\mathrm{PM}_{2.5-10} \mathrm{Ni}$ showed that $\mathrm{OC}$ was still significantly associated with decreased RHI, and although both exposures showed weaker associations when co-regressed, the confounding was much smaller for OC than for $\mathrm{Ni}$ ( $21 \%$ decrease for OC, $65 \%$ decrease for Ni, Additional file 1: Figure S6). An unmeasured determinant of the $\mathrm{OC}$ fraction may be important, perhaps endotoxins. Compared with smaller PM size fractions there is more endotoxin in the coarse than fine PM fractions and consequently greater inflammatory responses by alveolar macrophages [49].

This study enabled us to demonstrate for the first time that associations of impaired microvascular function with primary markers of fossil fuel combustion were stronger for subjects who were former smokers. Given the reduced sample size among subgroups, it is difficult to further explore explanations for the observed effect modification by former smokers. We infer from the present results that former smokers may be more 
susceptible to exposure to air pollution. It is also possible that being a former smoker is an indicator of other unmeasured co-morbidities or lifestyle habits that place them at increased risk. The finding that subjects who were obese showed stronger associations of impaired microvascular function with air pollutants needs further investigation. However, consistent with our current results, a review by Weichenthal et al. [50] reported that 11 of 14 previous panel studies investigating the health effects of $\mathrm{PM}_{2.5}$ on physiological measures of cardiovascular health reported greater adverse responses with exposure to $\mathrm{PM}_{2.5}$ among obese adults. It is possible that obesity is associated with enhancement of the proinflammatory effect of air pollution and thus increased susceptibility [51].

Growing evidence $[1,52]$ supports the view that air pollutants with higher pro-oxidant potential are more capable of generating oxidative stress and inducing inflammation at both respiratory [53, 54] and systemic sites [54] in human population studies. This process may alter the function of the vascular endothelium and initiate endothelial dysfunction. In the present study, we measured the effects of short-term exposure but it is possible that the observed acutely-impaired endothelial function can result in long-term effects following repeated insults as evidenced by recent cohort studies of long-term exposure to traffic-related air pollutants and the development of atherosclerosis $[55,56]$.

One limitation of our study is that most of our exposure data were obtained from central monitoring stations ranging from 1.58 to $16.37 \mathrm{~km}$ to the subject's residential address. However, any exposure misclassification is likely to be non-differential, leading to an underestimation of the health effect of air pollution [57]. This is validated by our sensitivity analysis in that we did not observe notable changes by restricting the analysis to subjects living within a smaller radius around the air monitoring stations (Additional file 1: Figure S4). Another limitation of our study was that all of the health measures were collected in clinical settings rather than in the home, resulting in non-ambient exposures on the way to the clinic. Further, the lack of data on daily personal exposure prevented us from directly comparing associations with ambient daily data. We also did not assess daily PM composition, which could have provided information on the lag effect of chemical components. Finally, we did not collect information on subjects' daily diet, which may affect vascular function, and as with any observational study there is the possibility of unmeasured confounding factors in the relationships of interest. Strengths of this study include the repeated measures study design, which enabled control of potentially confounding personal characteristics, the use of noninvasive and relatively technician-independent measures of microvascular function, and the detailed exposure estimation of PM composition and oxidative potential of different particle size-fractions.

\section{Conclusions}

In summary, our results show that microvascular endothelial dysfunction is associated with ambient air pollutants and that these pollutants are linked to primarily mobile sources. Oxidative potential measured both by abiotic DTT and macrophage ROS assays was associated with microvascular dysfunction further highlighting their potential roles in the overall associations between air pollutants and vascular function. European Union National Emission Ceilings and U.S. Environmental Protection Agency-regulated ambient $\mathrm{PM}_{2.5}$ mass measurements may not adequately represent risk for cardiovascular disease because they are uncharacterized by composition, source or oxidative potential. Further data are needed using measurements of organic components and oxidative potential across several PM size-fractions and with personal exposures. However, our findings provide clues to the potential mechanisms behind the effects of air pollution on cardiovascular disease and provide further justification of the importance of simultaneously measuring particulate air pollution composition, toxicity and source tracers in assessing adverse cardiovascular health effects.

\section{Additional file}

Additional file 1: Associations between microvascular function and short-term exposure to traffic-related air pollution and particulate matter oxidative potential supplementary material. (PDF 1.45 mb)

\section{Abbreviations}

AIC, Akaike's information criterion; BC, black carbon; BMI, body mass index; $\mathrm{Cl}$, confidence interval; CO, carbon monoxide; DTT, dithiothreitol; EC, elemental carbon; FMD, flow-mediated dilatation; $\mathrm{HDL}$, high-density lipoprotein; LDL, low-density lipoprotein; $\mathrm{NO}_{x}$, nitrogen oxides; $\mathrm{O}_{3}$, ozone $\mathrm{OC}$, organic carbon; $\mathrm{PAH}$, polycyclic hydrocarbons; $\mathrm{PM}_{10}$, particulate matter with aerodynamic diameter $<10 \mu \mathrm{m}$; $\mathrm{PM}_{2.5}$, particulate matter with aerodynamic diameter $<2.5 \mu \mathrm{m}$; $\mathrm{RHI}$, reactive hyperemia index; $\mathrm{ROS}$, reactive oxygen species; SF-ICPMS, sector field inductively-coupled plasma mass spectrometry; USC, the University of Southern California

\section{Acknowledgements}

We thank the staff and students at the University of California Irvine Department of Epidemiology, and staff at the Wisconsin State Laboratory of Hygiene for their assistance with the chemical analysis. We also acknowledge the support of University of Southern California's Provost and Viterbi PhD fellowships.

\section{Funding}

This study was supported by grant number R01 ES012243 from the National Institute of Environmental Health Sciences, U.S. National Institutes of Health $(\mathrm{NIH})$, and Grant UL1 TR000153 from the National Center for Research Resources and the National Center for Advancing Translational Sciences, NIH, and by contract number BPG-55175 administered by the South Coast Air Quality Management District (SCAQMD). The content is solely the responsibility of the authors and does not necessarily represent the official views of the $\mathrm{NIH}$ or SCAQMD. 


\section{Availability of data and materials}

De-identified data are available from the principal investigator by written request to legitimate scientific investigators capable of using the data. Subject confidential data will not be shared.

\section{Authors' contributions}

XZ participated in the data collection of microvascular function, performed data analysis, and drafted the manuscript. NS assisted in study design, personal $\mathrm{NO}_{\mathrm{x}}$ assay, and editing of manuscript. $\Pi T$ performed the statistical modeling. DG designed the study's analytic strategy, interpretation of data, and editing of manuscript. JJ, MS, SH and PP collaborated on the PM sample collection and design, particle composition analysis, and editing of manuscript. JL assisted in study design, and editing of manuscript. RD developed the study design, participated in data analysis, led the data interpretation, and editing of manuscript. All authors read and approved the final version of the manuscript.

\section{Competing interests}

The author declare that they have no competing interests.

\section{Consent for publication}

Not applicable.

\section{Ethics approval and consent to participate}

This study was approved by the institutional Review Board of the University of California, Irvine. All subjects provided written informed consent before participation.

\section{Author details}

'Department of Epidemiology, School of Medicine, University of California, Irvine, Irvine 224 Irvine Hall, Irvine, CA 92617-7555, USA. ²Department of Statistics, School of Information and Computer Sciences, University of California, Irvine, Irvine, CA, USA. ${ }^{3}$ Environmental Chemistry and Technology Program, University of Wisconsin-Madison, Madison, WI, USA. ${ }^{4}$ Department of Civil and Environmental Engineering, Viterbi School of Engineering, University of Southern California, Los Angeles, CA, USA. ${ }^{5}$ Susan Samueli Center for Integrative Medicine, and Cardiology Division, Department of Medicine, School of Medicine, University of California, Irvine, Irvine, CA, USA.

\section{Received: 20 November 2015 Accepted: 8 June 2016}

\section{Published online: 26 July 2016}

\section{References}

1. Brook RD, Rajagopalan S, Pope III CA, Brook JR, Bhatnagar A, Diez-Roux AV, et al. Particulate matter air pollution and cardiovascular disease: An update to the scientific statement from the American Heart Association. Circulation. 2010;121:2331-78.

2. Gold DR, Mittleman MA. New insights into pollution and the cardiovascular system 2010 to 2012. Circulation. 2013;127:1903-13.

3. Brook RD, Urch B, Dvonch JT, Bard RL, Speck M, Keeler G, et al. Insights into the mechanisms and mediators of the effects of air pollution exposure on blood pressure and vascular function in healthy humans. Hypertension. 2009;54:659-67.

4. Miller MR, Shaw CA, Langrish JP. From particles to patients: oxidative stress and the cardiovascular effects of air pollution. Future Cardiol. 2012;8:577-602.

5. Rubinshtein R, Kuvin JT, Soffler M, Lennon RJ, Lavi S, Nelson RE, et al. Assessment of endothelial function by non-invasive peripheral arterial tonometry predicts late cardiovascular adverse events. Eur Heart J. 2010;31:1142-8.

6. Matsuzawa Y, Sugiyama S, Sumida H, Sugamura K, Nozaki T, Ohba K, et al. Peripheral endothelial function and cardiovascular events in high-risk patients. J Am Heart Assoc. 2013;2:e000426.

7. Ljungman PL, Wilker EH, Rice MB, Schwartz J, Gold DR, Koutrakis P, et al. Short-term exposure to air pollution and digital vascular function. Am J Epidemiol. 2014;180:482-9.

8. Louwies T, Panis LI, Kicinski M, De Boever P, Nawrot TS. Retinal microvascular responses to short-term changes in particulate air pollution in healthy adults. Environ Health Perspect. 2013;121:1011-6.

9. Weichenthal S, Hatzopoulou M, Goldberg MS. Exposure to traffic-related air pollution during physical activity and acute changes in blood pressure, autonomic and micro-vascular function in women: a cross-over study. Part Fibre Toxicol. 2014:11:70

10. Delfino RJ, Sioutas C, Malik S. Potential role of ultrafine particles in associations between airborne particle mass and cardiovascular health. Environ Health Perspect. 2005;113:934-46.

11. Araujo JA, Barajas B, Kleinman M, Wang X, Bennett BJ, Gong KW, et al. Ambient particulate pollutants in the ultrafine range promote early atherosclerosis and systemic oxidative stress. Circ Res. 2008;102:589-96.

12. Shirmohammadi F, Hasheminassab S, Saffari A, Schauer JJ, Delfino RJ, Sioutas $C$. Fine and ultrafine particulate organic carbon in the Los Angeles basin: trends in sources and composition. Sci Total Environ. 2015;541:1083-96.

13. Shirmohammadi F, Hasheminassab S, Wang D, Saffari A, Schauer JJ, Shafer MM, et al. Oxidative potential of coarse particulate matter (PM) and its relation to water solubility and sources of trace elements and metals in the Los Angeles Basin. Environ Sci Process Impacts. 2015;17:2110-21.

14. Sioutas C, Delfino RJ, Singh M. Exposure assessment for atmospheric ultrafine particles (UFPs) and implications in epidemiologic research. Environ Health Perspect. 2005;113:947-55.

15. Axtell AL, Gomari FA, Cooke JP. Assessing endothelial vasodilator function with the Endo-PAT 2000. J Vis Exp. 2010;44:2167.

16. Mengden T, Asmar R, Kandra A, Di Giovanni R, Brudi P, Parati G. Use of automated blood pressure measurements in clinical trials and registration studies: data from the VALTOP Study. Blood Press Monit. 2010;15:188-94.

17. Birch ME, Cary RA. Elemental carbon-based method for monitoring occupational exposures to particulate diesel exhaust. Aerosol Sci Tech. 1996;25:221-41.

18. Stone EA, Snyder DC, Sheesley RJ, Sullivan AP, Weber RJ, Schauer JJ. Source apportionment of fine organic aerosol in Mexico City during the MILAGRO experiment 2006. Atmos Chem Phys. 2008;8:1249-59.

19. Landreman AP, Shafer MM, Hemming JC, Hannigan MP, Schauer JJ. A macrophage-based method for the assessment of the reactive oxygen species (ROS) activity of atmospheric particulate matter (PM) and application to routine (daily-24 h) aerosol monitoring studies. Aerosol Sci Tech. 2008:42:946-57.

20. Li N, Sioutas C, Cho A, Schmitz D, Misra C, Sempf J, et al. Ultrafine particulate pollutants induce oxidative stress and mitochondrial damage. Environ Health Perspect. 2003;11::455-60.

21. Shinyashiki M, Eiguren-Fernandez A, Schmitz DA, Di Stefano E, Li N, Linak WP, et al. Electrophilic and redox properties of diesel exhaust particles. Environ Res. 2009;109:239-44.

22. Ogawa \& Company, U., Inc. $\mathrm{NO}, \mathrm{NO}_{2}, \mathrm{NO}_{x}$ and $\mathrm{SO}_{2}$ Sampling Protocol Using The Ogawa Sampler. 2006. http://ogawausa.com/wp-content/uploads/2014/ 04/prono-noxno2so206.pdf. Accessed 22 Jan. 2015.

23. Anderson GB, Bell ML, Peng RD. Methods to calculate the heat index as an exposure metric in environmental health research. Environ Health Perspect. 2013;121:1111-9.

24. Green DJ, Maiorana A, O'Driscoll G, Taylor R. Effect of exercise training on endothelium-derived nitric oxide function in humans. J Physiol. 2004:561:1-25.

25. Gokce N, Duffy SJ, Hunter LM, Keaney JF, Vita JA. Acute hypertriglyceridemia is associated with peripheral vasodilation and increased basal plow in healthy young adults. Am J Cardiol. 2001;88:153-9.

26. Cook RD. Detection of influential observation in linear-regression. Technometrics. 1977;19:15-8.

27. Itamar Medical I. EndoPATM 2000 Device User Manual. 2015. http://www. itamar-medical.com/wp-content/uploads/2016/02/OM1695214.pdf. Accessed 26 Feb. 2016.

28. Schauer JJ, Rogge WF, Hildemann LM, Mazurek MA, Cass GR, Simoneit BRT. Source apportionment of airborne particulate matter using organic compounds as tracers. Atmos Environ. 1996;30:3837-55.

29. Mills NL, Tornqvist H, Robinson SD, Gonzalez M, Darnley K, MacNee W, et al. Diesel exhaust inhalation causes vascular dysfunction and impaired endogenous fibrinolysis. Circulation. 2005;112:3930-6.

30. Tornqvist $\mathrm{H}$, Mills NL, Gonzalez M, Miller MR, Robinson SD, Megson IL, et al. Persistent endothelial dysfunction in humans after diesel exhaust inhalation. Am J Respir Crit Care Med. 2007;176:395-400.

31. Schauer JJ, Cass GR. Source apportionment of wintertime gas-phase and particle-phase air pollutants using organic compounds as tracers. Environ Sci Technol. 2000;34:1821-32.

32. Daher N, Hasheminassab S, Shafer MM, Schauer JJ, Sioutas C. Seasonal and spatial variability in chemical composition and mass closure of ambient 
ultrafine particles in the megacity of Los Angeles. Environ Sci Process Impacts. 2013;15:283-95.

33. Saffari A, Hasheminassab S, Wang DB, Shafer MM, Schauer JJ, Sioutas C. Impact of primary and secondary organic sources on the oxidative potential of quasi-ultrafine particles (PM0.25) at three contrasting locations in the Los Angeles Basin. Atmos Environ. 2015;120:286-96.

34. Delfino RJ, Staimer N, Tjoa T, Arhami M, Polidori A, Gillen DL, et al. Association of biomarkers of systemic inflammation with organic components and source tracers in quasi-ultrafine particles. Environ Health Perspect. 2010;118:756-62.

35. Wittkopp S, Staimer N, Tjoa T, Stinchcombe T, Daher N, Schauer JJ, et al. Nrf2-related gene expression and exposure to traffic-related air pollution in elderly subjects with cardiovascular disease: an exploratory panel study. J Expo Sci Environ Epidemiol. 2015;26:141-9.

36. Cho AK, Sioutas C, Miquel AH, Kumagai Y, Schmitz DA, Singh M, et al. Redox activity of airborne particulate matter at different sites in the Los Angeles Basin. Environ Res. 2005;99:40-7.

37. Li R, Ning Z, Majumdar R, Cui J, Takabe W, Jen N, et al. Ultrafine particles from diesel vehicle emissions at different driving cycles induce differential vascular pro-inflammatory responses: implication of chemical components and NF-kappaB signaling. Part Fibre Toxicol. 2010;7:6.

38. Bonvallot V, Baeza-Squiban A, Baulig A, Brulant S, Boland S, Muzeau F, et al. Organic compounds from diesel exhaust particles elicit a proinflammatory response in human airway epithelial cells and induce cytochrome p450 1A1 expression. Am J Respir Cell Mol Biol. 2001;25:515-21.

39. Higashi Y, Noma K, Yoshizumi M, Kihara Y. Endothelial function and oxidative stress in cardiovascular diseases. Circ J. 2009;73:411-8.

40. Ayres JG, Borm P, Cassee FR, Castranova V, Donaldson K, Ghio A, et al. Evaluating the toxicity of airborne particulate matter and nanoparticles by measuring oxidative stress potential - a workshop report and consensus statement. Inhal Toxicol. 2008;20:75-99.

41. Schneider A, Neas L, Herbst MC, Case M, Williams RW, Cascio W, et al. Endothelial dysfunction: associations with exposure to ambient fine particles in diabetic individuals. Environ Health Perspect. 2008;1 16:1666-74.

42. Zanobetti A, Luttmann-Gibson H, Horton ES, Cohen A, Coull BA, Hoffmann $B$, et al. Brachial artery responses to ambient pollution, temperature, and humidity in people with type 2 diabetes: a repeated-measures study. Environ Health Perspect. 2014;122:242-8.

43. Williams R, Brook R, Bard R, Conner T, Shin H, Burnett R. Impact of personal and ambient-level exposures to nitrogen dioxide and particulate matter on cardiovascular function. Int J Environ Health Res. 2012;22:71-91.

44. Struijker-Boudier HA, Rosei AE, Bruneval P, Camici PG, Christ F, Henrion D, et al. Evaluation of the microcirculation in hypertension and cardiovascular disease. Eur Heart J. 2007;28:2834-40.

45. Flammer AJ, Anderson T, Celermajer DS, Creager MA, Deanfield J, Ganz P, et al. The assessment of endothelial function from research into clinical practice. Circulation. 2012;126:753-67.

46. Rodes CE, Holland DM. Variations of No, No2 and O-3 concentrations downwind of a Los-Angeles freeway. Atmos Environ. 1981;15:243-50.

47. Weschler CJ. Ozone in indoor environments: concentration and chemistry. Indoor Air. 2000;10:269-88.

48. Ntziachristos L, Froines JR, Cho AK, Sioutas C. Relationship between redox activity and chemical speciation of size-fractionated particulate matter. Part Fibre Toxicol. 2007;4:5.

49. Becker S, Soukup JM, Sioutas C, Cassee FR. Response of human alveolar macrophages to ultrafine, fine, and coarse urban air pollution particles. Exp Lung Res. 2003;29:29-44.

50. Weichenthal S, Hoppin JA, Reeves F. Obesity and the cardiovascular health effects of fine particulate air pollution. Obesity. 2014;22:1580-9.

51. O'Neill MS, Veves A, Sarnat JA, Zanobetti A, Gold DR, Economides PA, et al. Air pollution and inflammation in type 2 diabetes: a mechanism for susceptibility. Occup Environ Med. 2007;64:373-9.

52. Delfino RJ, Staimer N, Vaziri ND. Air pollution and circulating biomarkers of oxidative stress. Air Qual Atmos Health. 2011;4:37-52.

53. Delfino RJ, Staimer N, Tjoa T, Gillen DL, Schauer JJ, Shafer MM. Airway inflammation and oxidative potential of air pollutant particles in a pediatric asthma panel. J Expo Sci Environ Epidemiol. 2013;23:466-73.

54. Delfino RJ, Staimer N, Tjoa T, Arhami M, Polidori A, Gillen DL, et al. Associations of primary and secondary organic aerosols with airway and systemic inflammation in an elderly panel cohort. Epidemiology. 2010;21:892-902.
55. Hajat A, Allison M, Diez-Roux AV, Jenny NS, Jorgensen NW, Szpiro AA, et al. Long-term exposure to air pollution and markers of inflammation coagulation, and endothelial activation a repeat-measures analysis in the Multi-Ethnic Study of Atherosclerosis (MESA). Epidemiology. 2015;26:310-20.

56. Rivera M, Basagana X, Aguilera I, Foraster M, Agis D, de Groot E, et al. Association between long-term exposure to traffic-related air pollution and subclinical atherosclerosis: the REGICOR study. Environ Health Perspect. 2013;121:223-30.

57. Zeger SL, Thomas D, Dominici F, Samet JM, Schwartz J, Dockery D, et al. Exposure measurement error in time-series studies of air pollution: concepts and consequences. Environ Health Perspect. 2000;108:419-26.

\section{Submit your next manuscript to BioMed Central and we will help you at every step:}

- We accept pre-submission inquiries

- Our selector tool helps you to find the most relevant journal

- We provide round the clock customer support

- Convenient online submission

- Thorough peer review

- Inclusion in PubMed and all major indexing services

- Maximum visibility for your research

Submit your manuscript at www.biomedcentral.com/submit
( ) BioMed Central 